\title{
10 health stories that mattered May 5-9
}

- Maternal deaths in Canada rose from 6 to 11 per 100000 births between 1990 and 2013, according to a report by the World Health Organization. During the same period, maternal deaths in the United States increased from 12 to 28 per 100000 births, though the global rate fell by $45 \%$ to an estimated 289000 deaths.

- Canada's provinces should "continue to work on reforms that would limit growth in health care expenditures," even though overall economic growth is projected to grow by $2.75 \%$ in 2015, states an economic forecast by the Organisation for Economic Co-operation and Development.

- Health Canada's credibility and ability to make evidence-based decisions may have been diminished by changes to its library services, according to internal documents obtained by $\mathrm{CBC}$ News. The department moved its physical collection offsite and introduced a new computer system, but requests for research material has dropped $80 \%-90 \%$ and employees are using workarounds to obtain information, according to the documents.

- Canada's first marijuana vending machine is being operated by the $\mathrm{BC}$
Pain Society, a medical marijuana dispensary in Vancouver, British Columbia. It costs $\$ 20$ for an eighth of an ounce and $\$ 50$ for a half-ounce. Smaller quantities are available in repurposed gumball machines.

- The Nunavut Food Security Coalition has released the Nunavut Food Security Strategy and Action Plan. The strategy, intended to help improve the overall health and well-being of Nunavut residents, contains six key themes: programs and community initiative, policy and legislation, country food, store-bought food, local food production and life skills.

- Legislative changes in Alberta have granted the province's health minister greater fiscal control over Alberta Health Services. For the first time, the minister has power to approve the \$13-billion health authority's annual budget and direct how money is allocated within the health system.

- Nova Scotia has promised \$1 million in funding to improve the province's palliative care services. The money will go toward a new strategy that will include additional social services as well as the hiring of nurses and a palliative care coordinator.
- There is a growing risk of Lyme disease in humans and dogs in New Brunswick, warn researchers at Mount Allison University. By the fall of 2013, infection rates in dogs had risen to $7 \%$, compared to $1 \%$ three years earlier. It is estimated that one human will be infected for every six dogs infected.

- Prince Edward Island's process for licensing doctors is too cumbersome and needs to be streamlined or the province may lose opportunities to attract new physicians, according to Health Minister Doug Currie. The College of Physicians and Surgeons of Prince Edward Island claims the time frame for approval is similar to that in other provinces, most often taking between two days and two weeks, depending on whether a physician was trained in Canada or a foreign country.

- The Health Sciences Association of Saskatchewan voted $85.5 \%$ in favour of going on strike over unmet contract demands. The association represents 3000 specialized health care professionals in more than 30 professions. — Roger Collier, CMAJ

CMAJ 2014. DOI:10.1503/cmaj.109-4802 